\title{
Altered Expressions of Fibroblast Growth Factor Receptors and Alveolarization in Neonatal Mice Exposed to 85\% Oxygen
}

\author{
MIN SOO PARK, ESTHER RIEGER-FACKELDEY, BRANDON L. SCHANBACHER, ANGELA C. COOK, JOHN A. BAUER, \\ LYNETTE K. ROGERS, THOMAS N. HANSEN, STEPHEN E. WELTY, AND CHARLES V. SMITH
}

\begin{abstract}
Department of Pediatrics [M.S.P., E.R.-F., B.L.S., A.C.C., J.A.B., L.K.R., T.N.H., S.E.W., C.V.S.], Columbus Children's Research Institute; Columbus, Ohio 43205; Department of Pediatrics [M.S.P.], Yonsei University College of Medicine, Seoul, 120-752, Korea; Department of Neonatology [E.R.-F.], Klinikum Grosshadern, Ludwig Maximilian-University, 81377 Munich, Germany; Department of Pediatrics [T.N.H., C.V.S.], Seattle Children's Hospital Research Institute, Seattle, Washington 98101
\end{abstract}

\begin{abstract}
In the present study, we tested the hypothesis that exposure of newborn mice to sublethal hyperoxia would alter lung development and expressions of fibroblast growth factor receptors (FGFRs)-3 and FGFR-4. Newborn FVB mice were exposed to $85 \%$ $\mathrm{O}_{2}$ or maintained in room air for up to $14 \mathrm{~d}$. No animal mortality was observed, and body weight gains were not affected by hyperoxia. At postnatal d 7 and 14 (P7, P14), lungs of mice exposed to $85 \% \mathrm{O}_{2}$ showed fewer alveolar secondary crests and larger alveoli or terminal air spaces than did mice in room air. In pups kept in room air, lung levels of FGFR-3 and FGFR-4 mRNA were greater at P3 than at P1, but similar increases were not observed in hyperoxic mice. Immunoreactivity of FGFR-3 and FGFR-4 was lower in lungs of hyperoxic mice than in controls at P14. In pups kept in room air, lung fibroblast growth factor (FGF)-7 mRNA levels were greater at P14 than at P1, but similar changes were not observed in hyperoxic mice. The temporally and spatially specific alterations in the expressions of FGFR-3, FGFR-4, and FGF-7 in the mice exposed to hyperoxia may contribute to aberrant lung development. (Pediatr Res 62: 652-657, 2007)
\end{abstract}

$\mathrm{B}$ ronchopulmonary dysplasia (BPD) was described initially as lung injury- and repair-related effects that were associated with radiologic findings of streaky, fibrous densities, alternating with hyperlucent areas $(1,2)$. The primary risk factors were premature birth, respiratory distress, mechanical ventilation, and administration of supplemental oxygen $\left(\mathrm{FiO}_{2}\right.$ $>0.21$ ). Inflammation, problems in nutritional support, and comorbid conditions also contribute to the development of BPD. Modifications of therapeutic strategies have decreased the incidence of BPD, as the disease was described originally, but the overall incidence of BPD has not declined. The "new BPD" of recent years shows little acute injury and repair described by Northway et al. $(1,2)$, but is characterized by fewer and larger alveoli and less organized alveolar vascularization, suggesting arrested or disordered lung development. The events occurring during secondary septation of terminal gas exchange units and maturation of alveolar microvascula-

Received May 25, 2007; accepted August 4, 2007.

Correspondence: Charles Vincent Smith, Ph.D., Center for Developmental Therapeutics, Seattle Children's Hospital Research Institute, 1900 Ninth Avenue, Seattle, WA 98101; e-mail: charles.smith@seattlechildrens.org

Supported by GM44263 and HL068948. ture are therefore of particular interest in research on mechanisms responsible for the new BPD (3-8).

Lung development in humans normally progresses through sequential structural changes that are observed similarly in rats and mice, which, at term, exhibit lungs that structurally resemble human lungs at 26-30 wk of gestation (9). Infants born at this age frequently encounter respiratory problems, arising from immature pulmonary surfactant metabolism, respiratory drive and coordination, or other deficiencies. Prematurely delivered nonhuman primate models of BPD may mimic human development more closely than do rodent models, but practical constraints limit the investigations that can be explored with primate models $(4,5,10)$.

The lungs of newborn rodents are sufficient for extrauterine life and are adequate for maturation into normal adult lungs. Studies in rats and mice indicate that lung growth and development are associated with expressions of complex arrays of growth factors, receptors, and signal transduction networks, for which temporal and spatial relationships are critical (1113). The working hypothesis for many studies is that altered expressions of these growth effector networks caused by exposure to stressors associated with BPD mediate disordered lung development.

Although developmental immaturity, volutrauma, inflammation, and other factors may contribute to the development of BPD, in newborn rats and mice, hyperoxia alone is sufficient to cause the arrested lung development that is characteristic of the new BPD. Similar effects have been reported in human infants born prematurely and treated with supplemental oxygen, but not mechanically ventilated (14). In addition, room air $\left(\mathrm{FIO}_{2}=0.21\right)$ can constitute hyperoxia in very premature human infants (15).

Warner et al. (16) reported that newborn FVB mice exposed to $85 \% \mathrm{O}_{2}$ exhibited inhibition of alveolarization that resembled the altered lung development observed in human infants with the new BPD. Weinstein et al. (17) reported that mice with targeted disruption of expressions of fibroblast growth

Abbreviations: BPD, bronchopulmonary dysplasia; FGF, fibroblast growth factor; FGFR, fibroblast growth factor receptor; HIF, hypoxia-inducible factor; HPF, high-power field 
factor receptor-3 and FGFR-4 (fgfr- $3^{-/-}$fgfr- $4^{-1-}$ ), although appearing relatively normal at birth, were completely blocked in alveogenesis and failed to show any formation of secondary septa, resulting in emphysematous lungs similar to those observed by Warner et al. (16). The studies described in the present report were based on the model described by Warner et al. and were designed to test the hypothesis that inhibition of lung development by exposure of newborn mice to sublethal hyperoxia would be accompanied by altered expressions of FGFR-3 and FGFR-4.

\section{MATERIALS AND METHODS}

Animals. Time-dated pregnant FVB/N mice from Harlan Sprague-Dawley (Indianapolis, IN) arrived at the vivarium at least $5 \mathrm{~d}$ before term to acclimatize before delivery. Mice were maintained on standard laboratory food and water ad libitum and kept on a $12 \mathrm{~h} / 12 \mathrm{~h}$ light/dark cycle. Animal study protocols were approved by the IACUC at Columbus Children's Research Institute.

Oxygen exposure protocol. Newborn mice from pairs of pregnant dams delivering naturally within $6 \mathrm{~h}$ of each other were pooled and redistributed randomly to the two dams in separate cages within $12 \mathrm{~h}$ of birth. One group of pups was placed in $85 \% \mathrm{O}_{2}$, and the other group was maintained in room air. Nursing dams were rotated between the hyperoxic and room air litters every $24 \mathrm{~h}$ to avoid oxygen toxicity in the dams and to eliminate maternal effects between groups. Oxygen exposures were conducted in Plexiglas chambers, into which $\mathrm{O}_{2}$ was delivered through an oxygen blender to achieve a constant level of $85 \% \mathrm{O}_{2}$. Oxygen levels were monitored with an oxygen analyzer. Soda lime was placed in the chamber to absorb moisture and to prevent accumulation of $\mathrm{CO}_{2}$. Animals were monitored every $6 \mathrm{~h}$ for evidence of morbidity or mortality. Body weights were recorded at euthanasia.

Tissue preparation. On $\mathrm{P} 1, \mathrm{P} 3, \mathrm{P} 7$, and $\mathrm{P} 14$, animals were euthanized by intraperitoneal injections of $200 \mathrm{mg} / \mathrm{kg}$ of sodium pentobarbital and exsanguinated by carotid artery transection. In half of the animals, tracheas were cannulated with 25 -gauge Silastic catheters, and $10 \%$ neutral buffered formalin was instilled at $25 \mathrm{~cm} \mathrm{H}_{2} \mathrm{O}$ pressure over 5 min of equilibration. In the other animals, lungs were excised, freeze-clamped with liquid nitrogencooled aluminum tongs, and stored at $-80^{\circ} \mathrm{C}$ for molecular studies. During fixation, a pressure drop to below $20 \mathrm{~cm}$ of $\mathrm{H}_{2} \mathrm{O}$ was to be considered a leakage, and that specimen would have been excluded from analyses, but no leaks were observed. After $5 \mathrm{~min}$, tracheas were tied, and lungs were removed and fixed overnight in buffered formalin. Tissues were washed in phosphatebuffered saline five times and stored at $4^{\circ} \mathrm{C}$. Intact left and right lungs were serially dehydrated in increasing concentrations of ethanol and embedded in paraffin. Left lungs were cut transversely (perpendicular to longitudinal or craniocaudal axis of the animal) at the level of entry of the left main bronchus into the lung parenchyma to obtain 2-mm thick slices while the right lungs were cut coronally through all four lobes (along the longitudinal axis and perpendicular to dorsal-ventral axis) at the level of entry of the right main bronchus. The slices were oriented identically in paraffin blocks. In other animals, the lungs were excised, freeze-clamped with liquid nitrogen-cooled aluminum tongs, and stored at $-80^{\circ} \mathrm{C}$. The frozen lungs were used to assess mRNA and protein levels.

Isolation of total RNA and reverse transcription. Total RNAs were isolated through RNeasy procedure (Qiagen). The frozen tissues were homogenized in guanidine isothiocyanate-containing buffer with a rotor-stator (PowerGen 700, Fisher Scientific). The samples were applied to RNeasy mini columns, RNA were eluted in $50 \mu \mathrm{L}$ of water, and concentrations were measured at $260 \mathrm{~nm}$.

Purified total RNAs were reverse transcribed to cDNAs. Total RNAs were diluted to $100 \mathrm{ng} / \mu \mathrm{L}$, and $5 \mu \mathrm{L}(500 \mathrm{ng})$ of RNA was added to the total reaction volumes of $50 \mu \mathrm{L}$, containing $5.5 \mathrm{mM} \mathrm{MgCl}_{2}, 500 \mu \mathrm{M}$ each of dATP, dCTP, dGTP, and dTTP, $2.5 \mu \mathrm{M}$ random hexamers, $0.4 \mathrm{U} / \mu \mathrm{L}$ of RNase inhibitor, $1.25 \mathrm{U} / \mu \mathrm{L}$ of MultiScribe reverse transcriptase, and $1 \times$ TaqMan RT buffer. The reaction mixes were incubated at $25^{\circ} \mathrm{C}$ for $10 \mathrm{~min}$, followed by $30-\mathrm{min}$ incubation at $48^{\circ} \mathrm{C}$. The reactions were terminated by heating at $95^{\circ} \mathrm{C}$ for $5 \mathrm{~min}$.

Real-time polymerase chain reaction (PCR). Real-time PCR was performed in triplicate with the ABI PRISM 7700 Sequence Detection System (Applied Biosystems, Foster City, CA) in reaction volumes of $25 \mu \mathrm{L}$, containing $1 \times$ universal master mix, $300 \mathrm{nM}$ of each forward and reverse primer, and $200 \mathrm{nM}$ fluorescent probe (Applied Biosystems). The quality of the PCRs were assessed by comparisons of triplicate RT versus no template controls for each sample, using the 18s rRNAs as the internal positive controls. The amplification conditions consisted of an initial incubation at $50^{\circ} \mathrm{C}$ for $2 \mathrm{~min}$, followed by incubation at $95^{\circ} \mathrm{C}$ for $10 \mathrm{~min}$, and 40 cycles of $95^{\circ} \mathrm{C}$ for $15 \mathrm{~s}$ and $60^{\circ} \mathrm{C}$ for $1 \mathrm{~min}$. Primers and probes for mouse fibroblast growth factor-7, FGFR-3, FGFR-4, hypoxia-inducible factor (HIF)- $1 \alpha$, and ICAM-1 were designed and custom synthesized (Applied Biosystems). Primers for mouse FGFR-3 were 5'-GGAGCTTGGTCATGGAAAGT-3' and 5'-GTGTATGTCTGCCGGATGCT-3', while the probe was 5'-6FAMTGGTACCCTCCGATCGTGGCA-TAMRA- $3^{\prime}$. Primers for mouse FGFR-4 were $5^{\prime}$-ATCGTATTGGAGGCATTCG-3' and $5^{\prime}$-TCCGAGGGTACCACACTTTC- $3^{\prime}$, while the probe was $5^{\prime}-6$ FAM-TGCGCCACCAACACTGGAGC-TAMRA- $3^{\prime}$. Primers for mouse FGF-7 were $5^{\prime}$-GAACAGCTACAACATCATGGAAA-3' and 5'-CATAGAGTTTCCCTTCCTTGTTC-3', while the probe was 5'-6FAM-TCAGGACCGTGGCAGTTGGAA-TAMRA-3'. Primers for mouse HIF- $1 \alpha$ were $5^{\prime}$-CCAGCAGACCCAGTTACAGA- $3^{\prime}$ and $5^{\prime}$-ATCTTCTTTATTGTCCTTCGTCTCT-3', while the probe was $5^{\prime}$ 6FAM-CTACCATCACTGCCACTGCCACC-TAMRA-3'. Finally, primers for mouse ICAM-1 were $5^{\prime}$-ATCTCAGGCCGCAAGGG- ${ }^{\prime}$ and $5^{\prime}$ CGAAAGTCCGGAGGCTCC-3', while the probe was 5' -6FAM- TGGCATTGTTCTCTAATGTCTCCGAGGC-TAMRA-3'.

After completion of the PCRs, fluorescence intensity thresholds were set within the linear phase of the amplifications. The cycle number in which the threshold was crossed by the active reporter fluorescence was determined (cycle threshold, $\mathrm{C}_{\mathrm{T}}$ ). For relative quantitation of gene expression, we used the comparative $\mathrm{C}_{\mathrm{T}}$ method, which was determined by subtracting the $18 \mathrm{~s}_{\mathrm{T}}$ value from the corresponding target gene $\mathrm{C}_{\mathrm{T}}$ value [i.e. $\Delta \mathrm{C}_{\mathrm{T}}=\mathrm{C}_{\mathrm{T}}$ (target gene) $\left.-\mathrm{C}_{\mathrm{T}}(18 \mathrm{~s})\right]$. Values of $\Delta \Delta \mathrm{C}_{\mathrm{T}}$ were determined by subtracting $\Delta \mathrm{C}_{\mathrm{T}}$ of a chosen reference group, such as untreated control or wild type, from the $\Delta \mathrm{C}_{\mathrm{T}}$ of the respective test group [i.e. $\Delta \Delta \mathrm{C}_{\mathrm{T}}=\Delta \mathrm{C}_{\mathrm{T}}$ (test group) $-\Delta \mathrm{C}_{\mathrm{T}}$ (reference group)]. Relative amounts of target mRNAs were calculated as 2 to the power of $-\Delta \Delta \mathrm{C}_{\mathrm{T}}$ [i.e. target mRNA relative to reference group $=$ $2^{-\Delta \Delta \mathrm{CT}}$.

Morphometric analysis, image capture, and digital image analysis. For each time point, four to five high-power field (HPF) images per lung and three to four lungs per experimental group at each time point were characterized. Five photomicrographs per lung section were captured at the same anatomical sites at $64 \times$ magnification (Olympus BX-40 microscope, Olympus Optical, New York, and a Diagnostic Instruments digital camera) under identical lighting conditions and optical settings. Images were analyzed using researchbased digital image analysis software (Image Pro Plus 4.0; Media Cybernetics, Silver Spring, MD) and a custom macro written for automated investigations of alveolar morphology. Terminal air spaces and alveoli within the image were selected by color segmentation, and incomplete air spaces (those touching the image edge) were excluded from analysis. The macro subroutine was used to determine the numbers of complete air spaces in the image, as well as the area and perimeter of each air space. Intra-animal and interobserver variabilities in these measurements were routinely less than $10 \%$. We determined the numbers of complete air spaces per HPF at $64 \times$ magnification, the average air space sizes (area in micrometers squared), average perimeters (in micrometers), average perimeter/area ratios $(1 / \mu \mathrm{m})$, and air space perimeter/area ratios. In addition, the numbers of secondary crests per image and the air space septal thicknesses were measured manually. Septal thickness measurements were made in a subset of six images each in room air and hyperoxic mice per time point. Secondary crests were identified as partitions that extended from the primary septa forming the walls of terminal sacs. Initial low secondary crests were observed as early as P1, as was reported previously (18). Numbers of alveolar secondary crests per HPF were counted for four to eight HPF images per lung and two to three lungs per group at each time point.

Immunohistochemistry, image capture, and digital image analysis. Tissues were immunostained with antibodies to FGFR-3, FGFR-4, HIF-1 $\alpha$, and CD-31 (all 1:100; Santa Cruz Biotech), as described previously. We used nonimmune rabbit IgG (1:750; Vector Laboratories, Burlingame, CA) in place of primary antibodies to evaluate the specificity of immunostaining. Diaminobenzidine $(0.06 \% \mathrm{wt} / \mathrm{vol})$ provided visualization of immunoreactivity and was followed by methyl green counterstaining.

Tissue sections, oriented identically, were visualized with an Olympus Optical BX-40 microscope $(12.5 \times$ or $200 \times$ magnification) and captured using a Polaroid (Cambridge, MA) digital camera $(1290 \times 960$ resolution). Images were segmented to eliminate background and nuclear counterstain from analysis. Optical densities (ODs) were determined for each image in alveoli or terminal air spaces, airways, and large vessels. ODs were multiplied by the total positively stained tissue areas to give integrated measures of staining intensities. More than 4000 air spaces were analyzed (seven to nine air spaces per HPF image, three to seven HPF images per lung, and three to four lungs per group). Intra- and interobserver variabilities were $<10 \%$. 


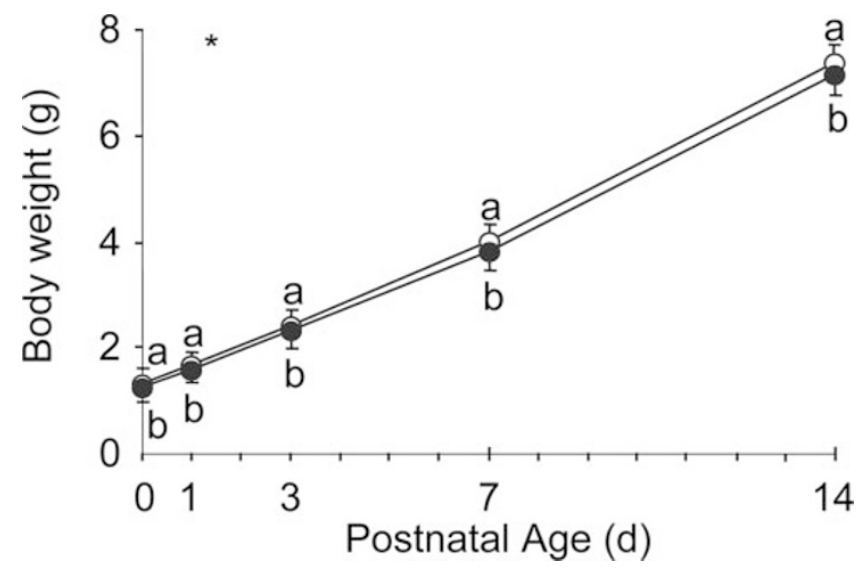

Figure 1. Body weights. Newborn FVB mice were weighed and exposed to $85 \% \mathrm{O}_{2}(\bullet)$ or room air $(\circ)$ and weighed again at euthanasia. Dams were exchanged daily between hyperoxia and room air. Data are mean \pm SEM, $n=8-10$. Effects were assessed by two-way ANOVA, with modified $t$ tests post hoc. *Effect of time; no effect of $\mathrm{FIO}_{2}$; no interactions. ${ }^{\mathrm{a}, \mathrm{b}}$ Data sharing common letters are different from each other; $p<0.05$.

Statistical analysis. Data are expressed as mean \pm SEM and were analyzed, using SPSS software, by two-way analysis of variance (ANOVA), with $\mathrm{FIO}_{2}$ and time as independent variables (19). Main group and interaction effects between the independent variables are signified as such in the respective figures. Modified $t$ tests were used for post hoc analyses, and differences between specific study groups, attributed at $p<0.05$, are indicated by groups sharing a common superscripted letter.

\section{RESULTS}

No pups died during exposures, and no signs of distress were observed in either group. Pups gained weight throughout, and body weights were not different between room air and hyperoxic animals (Fig. 1).

In lungs of room air mice, air spaces increased in number and decreased in size through P14. In hyperoxic mice, air spaces did not change similarly in size or number, resulting in fewer and larger air spaces in hyperoxic animals than in controls (Fig. 2). Inflammatory cell infiltration by neutrophils and hyaline membrane formation were not observed. No differences in fibrosis were observed between room air and hyperoxia groups (Masson's trichrome stain, data not shown).
Large, engorged blood vessels were prominent in lungs of hyperoxic animals at P14, but such vessels were not evident in controls.

The numbers of air spaces per HPF did not increase in either group of pups through P7. In the mice exposed to hyperoxia, fewer air spaces were observed at $\mathrm{P} 3$ than at $\mathrm{P} 1$ or $\mathrm{P} 7$ or in air-breathing pups at $\mathrm{P} 3$ (Fig. 3A). In the second week of life, air space numbers increased in room air mice, but not in hyperoxic mice. The lung air space counts exhibited effects of postnatal age and of $\mathrm{FiO}_{2}$, as well as an interaction. Air spaces decreased in size in the mice kept in room air, but not in lungs of hyperoxic animals (Fig. 3B). Air spaces in hyperoxic mice were larger than in room air controls at P3, P7, and P14. Air space cross-sectional circumference-to-area ratios increased with age in room air controls, but not in hyperoxic animals, other than a difference between hyperoxic animals at P3 and P14 (Fig. 3C). In addition, lungs of hyperoxic mice exhibited greater septal wall thicknesses at P14 $(5.9 \pm 0.3$ versus $4.3 \pm 0.3 \mu \mathrm{m}, p<0.05)$ than did control mice.

The numbers of secondary crests were not affected by hyperoxia in lungs observed at P1 or P3; however, at P7 and $\mathrm{P} 14$, the numbers of alveolar secondary crests in the animals maintained in room air were greater than the numbers observed in lungs of hyperoxic animals (Fig. 4). The numbers of secondary crests in lungs of hyperoxic mice at P14 were greater than at earlier time points, but the burst of crest formation observed in room air mice between P3 and P7 was not observed in hyperoxic animals (Fig. 4).

At P3, expressions of FGFR-3, FGF-R4, and FGF-7 mRNAs were higher in room air animals than at $\mathrm{P} 1$ and in hyperoxic animals (Fig. 5A-C). Between P3 and P7, lung levels of FGFR-3 and FGFR-4 mRNAs increased in hyperoxic mice, such that the levels were greater than at $\mathrm{P} 3$ and greater than at $\mathrm{P} 7$ in room air mice. Between P7 and P14, mRNA levels of both receptors declined in hyperoxic animals, whereas in the air-breathing animals, levels of mRNA for FGFR-3 did not change and FGFR-4 message increased.

Lung FGF-7 mRNA levels increased in room air mice to levels at P14 that were more than three times the levels at P1 (Fig. 5C), but no increase was observed in hyperoxic animals.

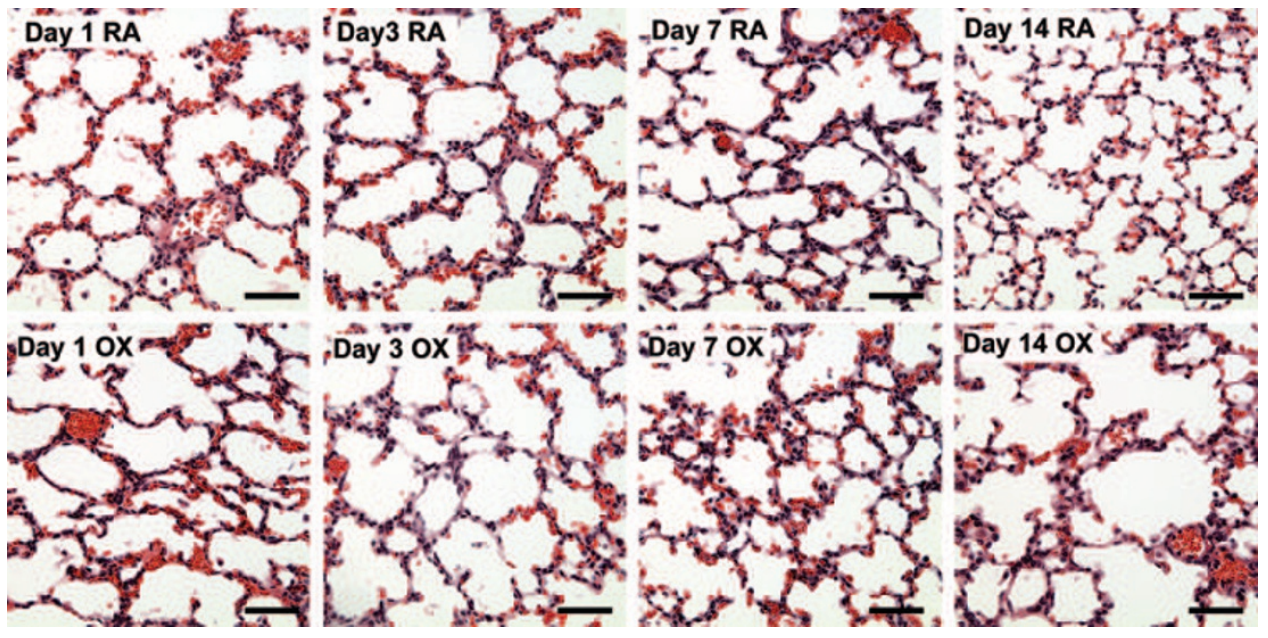

Figure 2. Lung histologies of newborn FVB mice exposed to $85 \% \mathrm{O}_{2}(\mathrm{OX})$ or left in room air (RA) for up to $14 \mathrm{~d}$ from birth. Lungs were inflation-fixed at $25 \mathrm{~cm}$ of $\mathrm{H}_{2} \mathrm{O}$ and stained with hematoxylin and eosin. Alveolarization is evident in mice kept in room air, with smaller and more numerous air space units, whereas lung development is arrested in hyperoxic mice. No increases in numbers of inflammatory cells were observed. Septa in the hyperoxic mice are slightly thicker than in room air mice. The images (magnification x60, bar $=50 \mu \mathrm{m}$ ) presented are representative of four to five HPF images per lung and three to four lungs per treatment group at each time point. Bar $=50 \mu \mathrm{m}$. 

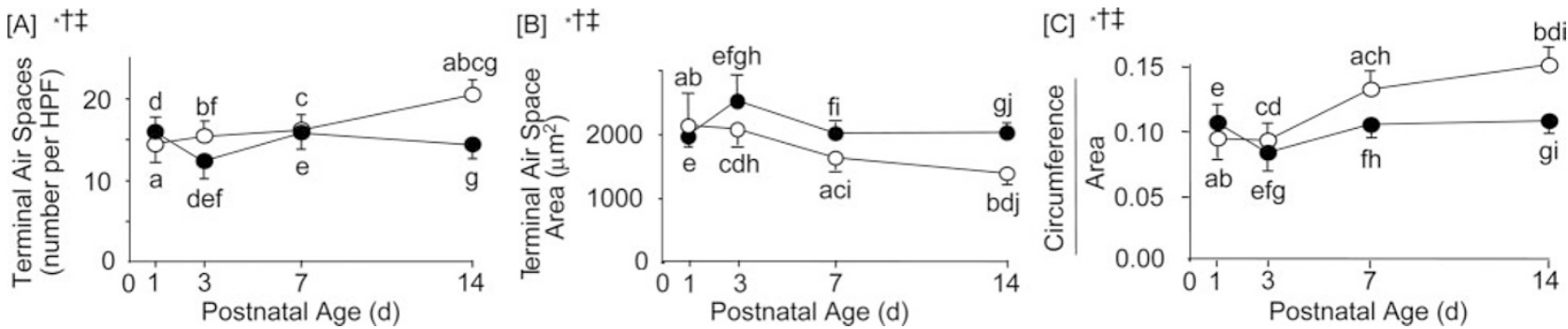

Figure 3. Morphometric effects of hyperoxia on lungs of newborn mice. Newborn FVB mice were exposed to $85 \% \mathrm{O}_{2}(\bullet)$ or were maintained in room air $(\bigcirc)$ for up to $14 \mathrm{~d}$. Lungs were inflation-fixed at $25 \mathrm{~cm}$ of $\mathrm{H}_{2} \mathrm{O}$. Data are mean \pm SEM of four to five HPF images per lung and three to four lungs per group at each time point. Data were analyzed by two-way ANOVA with modified $t$ tests post hoc. $(A)$ Numbers of air spaces per HPF $\left(\mathrm{N}_{\text {alv }}\right)$; $(B)$ Mean cross-sectional area of air spaces $\left(\mathrm{A}_{\text {alv }}\right) ;(C)$ Circumference-to-area ratios (LAR), a surrogate parameter for surface area-to-volume ratios (SVR). *Effect of time; †effect of FiO ${ }_{2}$; †interactions. ${ }^{\mathrm{a}-\mathrm{j}}$ Data sharing common letters are different, $p<0.05$.

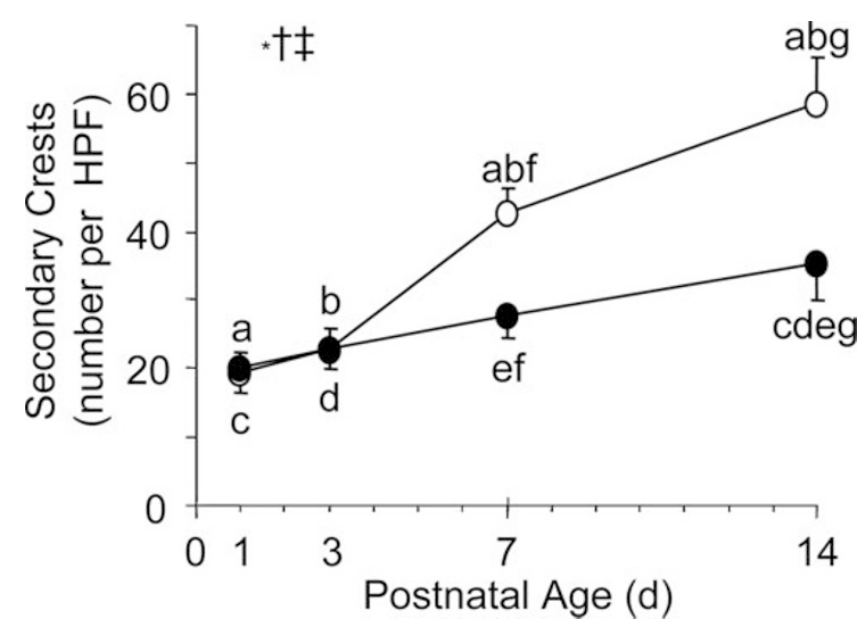

Figure 4. Alveolar secondary crest densities. Newborn FVB mice were exposed to $85 \% \mathrm{O}_{2}(-)$ or kept in room air $(\bigcirc)$. At P1, P3, P7, or P14, mice were euthanized, and lungs were fixed at $25 \mathrm{~cm} \mathrm{H}_{2} \mathrm{O}$. Numbers of alveolar secondary crests per HPF were counted. Data are mean \pm SEM, four to five HPF images per lung and three to four lungs per group. *Effect of time; †effect of $\mathrm{FIO}_{2}$; $\$$ interactions. ${ }^{\mathrm{a}-\mathrm{g}} \mathrm{Data}$ sets sharing common letters are different, $p<0.05$.

Lung HIF-1 $\alpha$ mRNA levels declined through P14 in both groups and showed no effects of hyperoxia (Fig. 5D). Intercellular adhesion molecule-1 (ICAM-1) mRNA levels in the lungs of the animals studied exhibited no effects of hyperoxia or age (data not shown).

Lung FGFR-3 immunoreactivity in room air mice was higher at $\mathrm{P} 14$ than at $\mathrm{P} 1$ and higher than in hyperoxic mice at P14 (Fig. 6 Al and A2). Lung FGFR-4 immunoreactivity was lower in room air mice at P14 than at P1, and levels in hyperoxic mice were even lower (Fig. $6 B 1$ and B2). Levels of HIF- $1 \alpha$ in all groups were below the measurable limits of quantitative immunohistochemistry. Inhibition of alveolarization in hyperoxic mice was accompanied by lower CD31 immunostaining densities in hyperoxic mice than in room air mice at P14 (Fig. $6 C 1$ and $C 2$ ), suggesting effects of sublethal hyperoxia on perialveolar vascularization in developing lungs.

\section{DISCUSSION}

The effects of exposure of newborn FVB mice to $85 \% \mathrm{O}_{2}$ that we observed replicated the effects on lung development reported by Warner et al. (16) and resemble the changes in
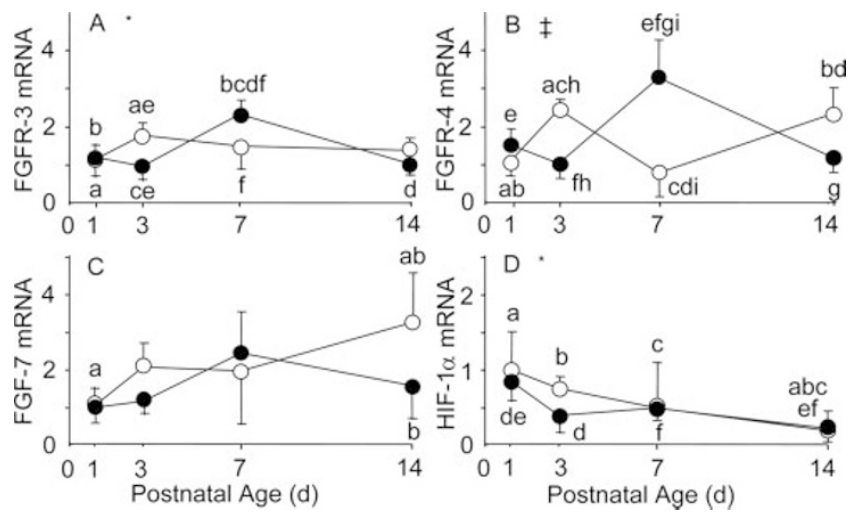

Figure 5. Relative mRNA expressions. Mice were exposed to $85 \% \mathrm{O}_{2}(-)$ or kept in room air $(\bigcirc)$ for up to $14 \mathrm{~d}$, euthanized with pentobarbital, and lungs were harvested and freeze-clamped immediately. Total RNAs were isolated and reverse transcribed. Relative gene expressions were assessed by real-time PCR, normalized against $18 \mathrm{~S}$ rRNA, and expressed as relative to the reference group (d 1 room air). Data are mean \pm SEM, $n=4-5$. (A) FGFR-3, $(B)$ FGFR-4, (C) FGF-7, and (D) HIF-1. *Effect of time; †effect of Fio2; \$interactions. ${ }^{\mathrm{a}-\mathrm{i}}$ Data sets sharing common letters are different, $p<0.05$.

lungs of premature infants who develop the new BPD (3). The absence of pup mortality, effects on body growth (Fig. 1), and pulmonary inflammation in the present studies differs from the report of Warner et al., and the reasons for the differences are unknown. However, the absence of undesired side effects diminishes concerns that developmental consequences are due to secondary responses rather than to primary effects of hyperoxia.

The changes in terminal air spaces in lungs of room air mice (Figs. 2 and 3) are consistent with normal secondary alveolarization between P3 and P14. The lack of similar changes in hyperoxic animals is consistent with inhibition of secondary alveolarization (Fig. 4). The decline in numbers of air spaces in the hyperoxic mice between P1 and P3 is not attributed to acute lung damage, which was not observed. Inflammatory responses, as to clear damaged cells, were not observed (Fig. 2 ). While important clinically, inflammatory responses elicited by acute lung damage or by infections would confound the interpretation of data regarding the effects of hyperoxia on lung development. The lower numbers of air spaces in the lungs of hyperoxic mice at $\mathrm{P} 3$ than at $\mathrm{P} 1$ are not attributed to inhibition of secondary alveolarization because the data indicate decreases in absolute numbers (Fig. 3). 

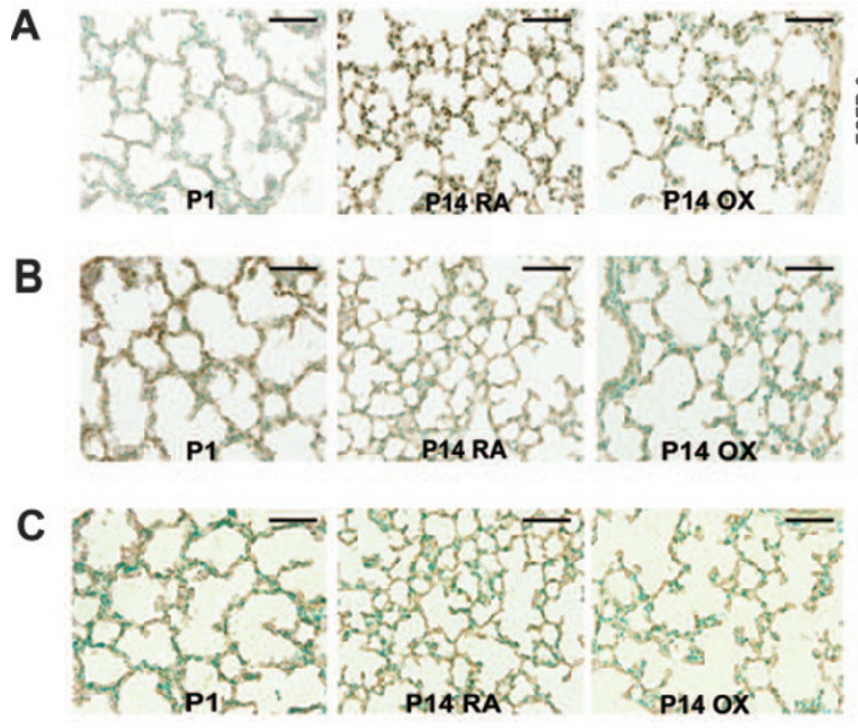

The altered expressions of FGFR-3 and FGFR-4 mRNAs in the lungs of hyperoxic mice (Fig. 5) suggest mechanisms for arrested lung development. Mice in which both $f g f r-3$ and $f g f r-4$ genes were knocked out, although appearing normal at birth, failed to grow normally, and lungs of these animals exhibited what Weinstein et al. (17) concluded was a lack of secondary septa. The histologic sections presented show structures that resemble secondary septal buds, suggesting that critical deficits in these mice lie downstream of initiation of secondary septation.

If hyperoxia-induced alterations in expression of FGFR-3 and FGFR-4 affect lung development, temporal patterns of expression are critical. Effects of sublethal hyperoxia on lung mRNA levels for FGFR-3 and FGFR-4 observed at P3 (Fig. 5) occur immediately before the marked increases in numbers of secondary septa observed in lungs of room air mice, but not in hyperoxic mice (Fig. 4). Although mRNA levels for FGFR-3 and FGFR-4 in the lungs of hyperoxic mice increased later, delayed increases in message levels may be ineffective. The existence of critical periods for expressions of growth regulatory molecules in lung alveolarization and maturation presumably reflect complex temporal and spatial patterns of expressions and essential interactions of a number of regulatory molecules $(11,20,21)$. Interventions with inappropriately timed enhancements of FGFR-3 and FGFR-4 expression would not be efficacious and could cause abnormal lung development.

Hyperoxia-induced enhancements of rates of receptor protein degradation may contribute to the lower levels of FGFR-3 and FGFR-4 proteins (Fig. 6). Reactive oxygen species (ROS) can activate growth factor receptors and stimulate subsequent internalization and degradation (22). Increased production of ROS in response to hyperoxia thus could stimulate degradation and turnover of FGFRs, thereby contributing to the effects that we observed.

Lower levels of endothelial immunostaining of CD31 (Fig. 6C) are consistent with previous reports of the inhibitory effects of hyperoxia on pulmonary vascularization $(5,23)$.
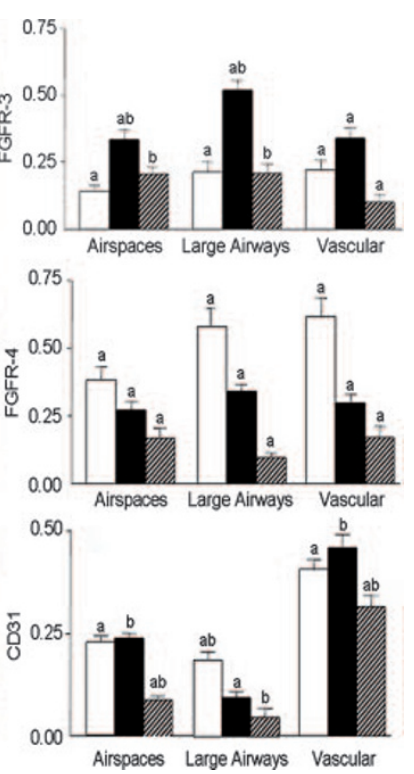

Figure 6. Quantitative immunohistochemistry for FGFR-3, FGFR-4, and CD31. Lung tissues of mice on the day of birth $(\mathrm{P} 1, \square)$, or maintained in room air $(\mathbf{\square})$ or exposed to $85 \% \mathrm{O}_{2}$ for $14 \mathrm{~d}$ (遍) were immunostained with antibodies to FGFR-3, FGFR-4, and CD31. The ODs per stained tissue areas were measured in terminal air spaces or alveoli, large airways, and large vessel regions. Immunohistochemical micrographs (magnification $80 \mathrm{x}$, bar $=50 \mu \mathrm{m}$ ) and ODs of immunostaining for FGFR-3, FGFR-4, and CD31 are shown. Data are mean \pm SEM of three to seven HPF images per lung and three to four lungs per group. ${ }^{\mathrm{a}, \mathrm{b}}$ Data sets sharing common letters are different, $p<0.05$.
Angiogenic factors, such as erythropoietin and VEGF, are down-regulated by hyperoxia (24-26). Hyperoxia would be expected to repress HIF- $1 \alpha$ expression, which, in turn, could down-regulate target genes (26). However, HIF-1 $\alpha$ levels were not detectable by the immunohistochemical methods used, and hyperoxia did not influence levels of HIF- $1 \alpha$ mRNA in lungs of newborn mice (Fig. 5D). HIF- $1 \alpha$ is degraded rapidly in normoxic tissues $(26,27)$, and hyperoxia should increase these rates. In baboons, HIF- $1 \alpha$ levels declined toward term and were absent at P2 (10). Effects of hyperoxia were only observed in baboons delivered preterm. The lack of effects of hyperoxia on HIF- $1 \alpha$ suggests that the apparent inhibition of angiogenesis in mice in the present study is secondary to the defect in alveolarization.

Swiss mice exposed to $65 \% \mathrm{O}_{2}$ for the first month of life showed deficits in lung growth and alveolarization that persisted after weaning to room air and were observable at $210 \mathrm{~d}$ of age (28). Adult mice subjected to caloric restriction showed decreases in alveolar numbers, but alveoli were restored by refeeding (29). The distinctions between the adult and neonatal models and between sublethal hyperoxia and dietary restriction need to be defined. The lack of compensatory alveolarization by P14 in the hyperoxic mice (Figs. 2 and 3), despite the increases in expressions of mRNA species of FGFR-3 and FGFR-4 observed at P7 (Fig. 5), suggests that some of the developmental windows that regulate lung maturation are relatively narrow; effective therapeutic interventions will need to accommodate temporal and spatial requirements for appropriate lung development. Accomplishing this goal will require detailed understanding of the highly complex mechanisms that regulate lung morphogenesis $(9,30)$.

\section{REFERENCES}

1. Northway WH Jr, Rosan RC, Porter DY 1967 Pulmonary disease following respirator therapy of hyaline-membrane disease. Bronchopulmonary dysplasia. N Engl J Med 276:357-368

2. Northway WH Jr 2001 Bronchopulmonary dysplasia: thirty-three years later. Pediatr Pulmonol 23:5-7 
3. Jobe AH, Bancalari E 2001 Bronchopulmonary dysplasia. Am J Respir Crit Care Med 163:1723-1729

4. Coalson JJ, Winter V, deLemos RA 1995 Decreased alveolarization in baboon survivors with bronchopulmonary dysplasia. Am J Respir Crit Care Med 152:640646

5. Coalson JJ, Winter VT, Siler-Khodr T, Yoder BA 1999 Neonatal chronic lung disease in extremely immature baboons. Am J Respir Crit Care Med 160:1333-1346

6. Bland RD 2005 Neonatal chronic lung disease in the post-surfactant era. Biol Neonate 88:181-191

7. Stenmark KR, Abman SH 2005 Lung vascular development: implications for the pathogenesis of bronchopulmonary dysplasia. Annu Rev Physiol 67:623-66

8. Burri PH 2006 Structural aspects of postnatal lung development-alveolar formation and growth. Biol Neonate 89:313-322

9. Warburton D, Schwarz M, Tefft D, Flores-Delgado G, Anderson KD, Cardoso WV 2000 The molecular basis of lung morphogenesis. Mech Dev 92:55-81

10. Asikainen TM, Ahmad A, Schneider BK, White CW 2005 Effect of preterm birth on hypoxia-inducible factors and vascular endothelial growth factor in primate lungs. Pediatr Pulmonol 40:538-546

11. Hokuto I, Perl AK, Whitsett JA 2003 Prenatal, but not postnatal, inhibition of fibroblast growth factor receptor signaling causes emphysema. J Biol Chem 278:415-421

12. Le Cras TD, Hardie WD, Deutsch GH, Albertine KH, Ikegami M, Whitsett JA, Korfhagen TR 2004 Transient induction of TGF-alpha disrupts lung morphogenesis, causing pulmonary disease in adulthood. Am J Physiol Lung Cell Mol Physiol 287:L718-L729

13. Maeda Y, Dave V, Whitsett JA 2007 Transcriptional control of lung morphogenesis. Physiol Rev 87:219-244

14. Hodgman JE 2003 Relationship between Wilson-Mikity syndrome and the new bronchopulmonary dysplasia. Pediatrics 112:1414-1415

15. Smith CV, Hansen TN, Martin NE, McMicken HW, Elliott SJ 1993 Oxidant stress responses in premature infants during exposure to hyperoxia. Pediatr Res 34:360365

16. Warner BB, Stuart LA, Papes RA, Wispe JR 1998 Functional and pathological effects of prolonged hyperoxia in neonatal mice. Am J Physiol 275:L110-L117

17. Weinstein M, Xu X, Ohyama K, Deng CX 1998 FGFR-3 and FGFR-4 function cooperatively to direct alveogenesis in the murine lung. Development 125:36153623
18. Scheuermann DW, Van Meir F, Adriaensen D, Timmermans JP, De Groodt-Lasseel MH 1988 Development of alveolar septa and formation of alveolar pores during the early postnatal period in the rat lung. Acta Anat (Basel) 131:249-261

19. Zar JH 1984 Biostatistical Analysis. Prentice-Hall, Englewood Cliffs, NJ

20. Simonet WS, DeRose ML, Bucay N, Nguyen HQ, Wert SE, Zhou L, Ulich TR, Thomason A, Danilenko DM, Whitsett JA 1995 Pulmonary malformation in transgenic mice expressing human keratinocyte growth factor in the lung. Proc Natl Acad Sci U S A 92:12461-12465

21. Tichelaar JW, Lu W, Whitsett JA 2000 Conditional expression of fibroblast growth factor-7 in the developing and mature lung. J Biol Chem 275:11858-11864

22. Marchese C, Maresca V, Cardinali G, Belleudi F, Ceccarelli S, Bellocci M, Frati L, Torrisi MR, Picardo M 2003 UVB-induced activation and internalization of keratinocyte growth factor receptor. Oncogene 22:2422-2431

23. Bhatt AJ, Pryhuber GS, Huyck H, Watkins RH, Metlay LA, Maniscalco WM 2001 Disrupted pulmonary vasculature and decreased vascular endothelial growth factor, Flt-1, and TIE-2 in human infants dying with bronchopulmonary dysplasia. Am J Respir Crit Care Med 164:1971-1980

24. Hosford GE, Olson DM 2003 Effects of hyperoxia on VEGF, its receptors, and HIF-2alpha in the newborn rat lung. Am J Physiol Lung Cell Mol Physiol 285:L161L168

25. Maniscalco WM, Watkins RH, D'Angio CT, Ryan RM 1997 Hyperoxic injury decreases alveolar epithelial cell expression of vascular endothelial growth factor (VEGF) in neonatal rabbit lung. Am J Respir Cell Mol Biol 16:557-567

26. Morel Y, Barouki R 1999 Repression of gene expression by oxidative stress. Biochem J 342:481-496

27. Salceda S, Caro J 1997 Hypoxia-inducible factor 1alpha (HIF-1alpha) protein is rapidly degraded by the ubiquitin-proteasome system under normoxic conditions. Its stabilization by hypoxia depends on redox-induced changes. J Biol Chem 272:22642-22647

28. Dauger S, Ferkdadji L, Saumon G, Vardon G, Peuchmaur M, Gaultier C, Gallego J 2003 Neonatal exposure to $65 \%$ oxygen durably impairs lung architecture and breathing pattern in adult mice. Chest 123:530-538

29. Massaro GD, Radaeva S, Clerch LB, Massaro D 2002 Lung alveoli: endogenous programmed destruction and regeneration. Am J Physiol Lung Cell Mol Physiol 283:L305-L309

30. Perl AK, Whitsett JA 1999 Molecular mechanisms controlling lung morphogenesis. Clin Genet 56:14-27 